\title{
EVALUASI KUALITAS WEBSITE DITINJAU DARI KEPUASAN USER DENGAN WEB ANALYTIC (STUDI KASUS PADA WEBSITE MAJALAH LIVINGETC INDONESIA)
}

\author{
Kim Ming \\ Universitas Bina Nusantara \\ Jl. K.H. Syahdan No.9, Palmerah Jakarta 11480, Indonesia \\ kimmingonline@gmail.com
}

\begin{abstract}
Abstrak: Tujuan penelitian ini evaluasi website livingetcindonesia.com untuk mendapatkan kualitas website apa saja yang tepat untuk meningkatkan kepuasan user sebagai media online majalah Livingetc dan sejauh mana tingkat kepuasan user terhadap penyajian website Livingetc. Kriteria kualitas website perceived usefulness, ease of use, ease of finding information, dan design/layout of page yang diteliti untuk mengetahui pengaruh terhadap kepuasan user. Analisa terhadap infrastruktur website sudah memenuhi kebutuhan web dan database server, struktur database, web analytics untuk mengetahui kunjungan user pada website dan wilayah/lokasi dimana user mengunjungi website. Hasil survei menunjukkan variabel Perceived usefullness, Ease of use, Ease of finding information, dan Design/Layout of page berpengaruh signifikan terhadap kepuasan user.
\end{abstract}

Kata kunci: Kepuasan user website, kualitas website, web analytics.

\begin{abstract}
:
The purpose of this study is to evaluate livingetcindonesia.com website, in order to improve user satisfaction as an online media and the extent to which the level of user satisfaction to the presentation of the website. The website criteria: perceived usefulness, ease of use, ease of finding information, and the design/layout of page is examined to determine the effect on user satisfaction. Analysis of site infrastructure has been meeting the needs of web and database servers, database structure, web analytics to determine the user visits the website and area/location where a user visiting the website. The survey results showed variable Perceived usefullness, Ease of use, Ease of finding information, and Design/Layout of page significant effect on user satisfaction.
\end{abstract}

Keywords: user satisfaction, website quality, web analytics

\section{PENDAHULUAN}

Kemajuan teknologi telah membawa perubahan pada industri media mulai dari mengumpulkan, menghasilkan, dan menyampaikan informasi. Sistem media tradisional mendistribusikan informasi melalui media cetak seperti koran dan majalah yang memerlukan siklus proses penyampaian informasi dengan mengubahnya menjadi bentuk cetak untuk disampaikan ke pelanggan. Kemajuan teknologi telah mengubah industri media dari bentuk cetak menjadi digital yang membuat pengumpulan dan distribusi informasi menjadi semakin mudah yang dikenal sebagai media baru [6].

Website telah menjadi hal penting dalam kehidupan dalam beberapa tahun untuk memberikan berbagai informasi. Website telah tumbuh dengan cepat dalam berbagai lingkup dan penggunaanya, dengan didukung kemajuan internet dan teknologi web dan standar web yang berkembang. Banyak website yang ada saat ini tidak memperhatikan kriteria pembuatan website yang baik dan benar, meskipun panduan kriteria untuk membuat website yang baik telah beredar secara gratis. Menurut survei Unica, website digunakan sebesar $57 \%$ untuk menyampaikan informasi ke pelanggan [24]. Website menyajikan informasi yang lebih cepat dan muktahir kepada pelanggan tanpa harus melalui media cetak terlebih dahulu.

Livingetc sebagai salah satu media dengan segmentasi pasar interior design dan gaya hidup tentunya tidak mau ketinggalan dalam memanfaatkan website dan media sosial sebagai sarana komunikasi terhadap pelanggan. Website majalah Livingetc bagi pelanggan di Indonesia dapat diakses melalui www. livingetcindonesia.com dengan media sosial facebook di www.facebook.com/livingetcindo dan twitter di LivingetcIndo. American Advertising Federation (2006) mengadakan survei untuk menentukan efektivitas media yang memicu pelanggan untuk mengunjungi suatu website. Survei tersebut menunjukkan bahwa majalah merupakan media yang 
paling efektif untuk membuat pelanggan online dengan proporsi sebesar $26,0 \%$ disusul dengan tayangan televisi (broadcast TV) sebesar 17,8\%, televisi kabel (cable TV) sebesar 16,4\%, koran sebesar $13,7 \%$, radio sebesar $11,0 \%$, media umum sebesar $8,2 \%$, dan lainnya sebesar $6,9 \%$ [12]. Terdapat tiga kontribusi majalah dalam mengembangkan lalu lintas website (web traffic) yaitu: iklan majalah memberikan dampak yang signifikan dalam mengembangkan lalu lintas website, iklan majalah menghasilkan lalu lintas website yang mendorong pembelian, dan alamat website dalam iklan majalah meningkatkan kunjungan website secara signifikan.

Livingetc yang mempunyai tagline rumah modis dan bergaya (fashionable and stylish home) menyajikan fitur dekorasi, rumah, belanja, properti, perjalanan (travel), menu sajian (food and beverage), acara (event), dan kompetisi. Persepsi suatu media dipengaruhi oleh pengalaman yang diperoleh oleh pelanggan dari website yang dikunjungi. Pelanggan mungkin tidak memiliki cara untuk menilai operasi suatu media kecuali melalui pengalaman pelayanan yang diperoleh oleh pelanggan. Mengukur kualitas website merupakan langkah yang penting dalam mengembangkan suatu website yang sesuai dengan tujuan dan membantu pelanggan untuk mencapai tujuan yang diinginkan. Kepuasan user merupakan dasar untuk mengukur kualitas suatu website. Survei online adalah metode yang tepat untuk memperoleh sampel user yang representatif untuk mengukur kepuasan user [2].

Penelitian ini akan membahas mengenai kualitas website apa saja yang tepat untuk meningkatkan kepuasan user sebagai media online Livingetc dengan segmentasi interior dan gaya hidup, apakah user puas terhadap penyajian informasi yang diberikan pada website Livingetc dan faktor apa saja yang dapat meningkatkan kepuasan user, dan apakah kualitas website akan mempengaruhi kepuasan user website dan mempengaruhi intensitas kunjungan website? Penelitian ini bertujuan untuk mendapatkan kualitas website apa saja yang tepat untuk meningkatkan kepuasan user sebagai media online Livingetc dengan segmentasi interior dan gaya hidup, menjelaskan sejauh mana tingkat kepuasan user terhadap penyajian website Livingetc dan faktor apa saja yang meningkatkan kepuasan user, dan mendapatkan kriteria-kriteria kualitas website yang berpengaruh terhadap intensitas kunjungan dan kepuasan user website.

\section{HASIL PENELITIAN TERDAHULU}

Soud Almahamid (2010), penelitiannya menyelidiki hubungan perceived userfulness, perceived ease of use, perceived information quality, dan pandangan dalam penggunaan website e-government untuk mendapatkan informasi dan berinteraksi dengan warganya. Sistem e-government digunakan dengan mudah tetapi tidak menyediakan kualitas informasi yang baik, informasi yang ada pada website e-government tidak memenuhi kebutuhan usernya [1].

Luis Olsina et al (2002) melakukan penelitian atribut kualitas website yang ditujukan untuk website akademik. Penelitian mengambil sudut pandang teknis and mengidentifikasikan faktor-faktor yang terkait. Dengan menggunakan Website Quality Evaluation Method(WebQEM) dan softwarenya, penelitian dilakukan untuk menilai kualitas website dan aplikasinya. Mengukur indikator kualitas dapat membantu pihak yang berkepentingan untuk memahami dan meningkatkan kualitas website. Survei kuantitatif dan evaluasi website dengan domain tertentu seperti domain website ecommerce, domain website museum, domain website academic dan sebagainya, membantu evaluasi usability dengan kuesioner bersifat subjektif pengguna, suatu strategi dengan kekuatan dan kelemahan masing-masing [11].

Liu and Arnett (2000) menyebutkan empat faktor kualitas website utama terdiri dari kualitas informasi dan layanan, kegunaan sistem, playfulness, dan kualitas design. Organisasi yang memiliki website harus menyadari faktor-faktor ini. Berdasarkan hasil penelitian, beberapa rekomendasi yang dianjurkan yaitu organisasi dan web developer seharusnya secara aktif mencari jalan untuk meningkatkan informasi dan kualitas layanan melalui website, organisasi dan website designer seharusnya mengfokuskan pada bagaimana cara pengunjung menggunakan website, menggali keinginan yang tersembunyi pengunjung pada website dengan memotivasi pengunjung untuk berpartisipasi dan mempromosikan ketertarikan pengunjung dan fokusnya sehingga membantu mereka menikmati kunjungan ke website [10].

\section{METODE PENELITIAN}

Empat variable yang akan diteliti terhadap variable kepuasan user, variabel tersebut antara lain perceived usefulness, ease of use, ease of finding information, dan design/layout of page. Model penelitian ini menggunakan metode regresi sebagai berikut:

$$
Y=\beta_{0}+\beta_{1} X_{1}+\beta_{2} X_{2}+\beta_{3} X_{3}+\beta_{4} X_{4}+\varepsilon
$$

Dimana:

$$
\begin{aligned}
\mathrm{Y}= & \text { Kepuasan User } \\
\beta_{0}= & \text { Koefisien, nilai antara }-1 \text { sampai }+1 \\
\beta_{1}= & \text { Koefisien variabel } \mathrm{X}_{1}(\text { Perceived usefulness), } \\
& \text { nilai antara }-1 \text { sampai }+1
\end{aligned}
$$


$\beta_{2}=$ Koefisien variabel $X_{2}$ (Ease of use), nilai antara -1 sampai +1

$\beta_{3}=$ Koefisien variabel $X_{3}$ (Ease of finding information), nilai antara -1 sampai +1

$\beta_{4}=$ Koefisien variabel $\mathrm{X}_{4}($ Design/layout of page $)$, nilai antara -1 sampai +1

$\varepsilon=$ standar kesalahan penaksiran

Target populasi berjumlah 330 terdiri dari 80 karyawan yang bertugas pada majalah Livingetc Indonesia, 250 member facebook majalah Livingetc Indonesia. Sampel yang digunakan dalam penelitian ini, dihitung dengan rumus Slovin, tingkat kesalahan 5\% adalah 180 orang. Kuesioner akan disebarkan pada pengguna website Livingetc agar bisa didapatkan data yang akan diolah sebagai evaluasi website. Kuesioner akan disebarkan dengan menggunakan email dan website survei online terhadap seluruh responden.

\section{HASIL DAN PEMBAHASAN}

Hasil analisa data survei yang telah diperoleh dari kuesioner yang telah disebarkan melalui survei online, email atau diberikan langsung kepada user. Data kuesioner yang terkumpul direkapitulasi secara menyeluruh. Responden survei berdasarkan jenis kelamin terdapat jumlah responden wanita $(70 \%)$ lebih banyak dari responden pria (30\%), responden survei berdasarkan usia terdapat jumlah responden berusia 20-40 tahun lebih banyak dari usia lainnya (88\%), responden berdasarkan pendidikan terakhir terdapat jumlah responden berpendidikan S1 (71\%) paling dominan dan Diploma (14\%), responden berdasarkan seberapa sering mengakses website livingetcindonesia.com yang paling banyak ditujukan beberapa kali dalam sebulan (73\%), dan responden berdasarkan waktu yang paling sering mengakses website livingetcindonesia.com oleh user dilakukan pada jam 12.00-18.00 dan berikutnya pada jam 06.00 -12.00 .

Hasil uji validitas dan reliabilitas menggunakan Cronbach Alpha pada program SPSS 20, akan terlihat nilai corrected item, jika dibawah 0,3 maka item tersebut tidak valid dan harus dibuang, sedangkan reliabilitas jika dibawah 0.6 maka dinyatakan tidak reliable. Hasil uji validitas setiap instrumen pertanyaan untuk 30 responden pada survei awal terhadap masing-masing variabel. Hasil uji validitas terhadap variabel-variabel yang dipilih dinyatakan valid dan reliabel. Besar nilai $\mathrm{R}$ square adalah 0.879 berarti $87.9 \%$ kepuasan user website dari $100 \%$ yang diharapkan berdasarkan variabel-variabel yang dipilih. Uji Anova menunjukkan hubungan keseluruhan antara variabel independen berpengaruh signifikan terhadap variabel dependen kepuasan user. Uji hipotesis didapatkan persamaan regresi sebagai berikut:

$\mathrm{Y}=0.575+0.238 \mathrm{~b}_{1}+0.145 \mathrm{~b}_{2}+0.285 \mathrm{~b}_{3}+0.183 \mathrm{~b}_{4}$

Tabel 1 Statistik Deskriptif

\begin{tabular}{cccc}
\hline & Mean & Std. Deviation & $\mathrm{N}$ \\
\hline $\mathrm{Y}$ & 3.4910 & .19271 & 180 \\
$\mathrm{X} 1$ & 3.4565 & .33628 & 180 \\
$\mathrm{X} 2$ & 3.3236 & .45441 & 180 \\
$\mathrm{X} 3$ & 3.4636 & .34798 & 180 \\
$\mathrm{X} 4$ & 3.4213 & .43455 & 180 \\
\hline
\end{tabular}

Hasil analisis kuesioner diatas dapat diambil kesimpulan sebagai berikut:

1) Variabel-variabel yang berpengaruh signifikan terhadap kepuasan user secara berurutan dari paling tinggi berdasarkan uji korelasi yakni ease of finding information, design/layout of page, perceived usefulness, dan ease of use.

2) Website livingetc telah menyediakan informasi berita, artikel, dan event promosi yang memuaskan pengunjung berdasarkan paling tinggi pengaruh variabel ease of finding information sehingga pengunjung maupun pelanggan menemukan informasi terlebih dahulu di website Livingetc.

3) Kualitas website yang baik akan meningkatkan kepuasan user, jika sebaliknya website akan ditinggalkan user dan tidak menjadi sumber informasi lagi.

4) Hasil survei ini menggunakan metode penelitian kuantitatif yang menitikberatkan hasilnya untuk mengukur kuantitas suatu objek yang tentunya akan memiliki kelemahan dalam mengukur peristiwa kualitatif misalnya situasi keadaan psikologis responden yang kurang mendukung saat mengisi kuesioner yang tentunya mempengaruhi objektivitas dan penilaian masingmasing responden terhadap kepuasan tentunya berbeda-beda tergantung pada sudut pandang masing-masing responden.

5) Kepuasan user tergantung pada variabel-variabel yang mempengaruhi, dilihat dari pertanyaanpertanyaaan kuesioner untuk meningkatkan kepuasan user, user mengharapkan adanya fitur yang dapat menambah interaksi antara user dengan pengelola website atau editor majalah Livingetc seperti forum dan chat, kelengkapan konten yang lebih lengkap, video yang mendukung artikel/berita yang ditayangkan. 


\section{PENUTUP}

Evaluasi website livingetcindonesia.com dapat disimpulkan sebagai berikut:

1) Hasil survei menunjukkan variabel Perceived usefullness, Ease of use, Ease of finding information, dan Design/Layout of page berpengaruh signifikan terhadap kepuasan user. Website livingetcindonesia.com telah menyajikan informasi terbaru dan lengkap yang mendukung sebagai media online majalah Livingetc dengan segmentasi interior dan gaya hidup.

2) Kepuasan user sebesar $87.9 \%$ terhadap website Livingetc dengan nilai korelasi variabel ease of finding information sebesar 0,544, perceived usefulness sebesar 0.417 , ease of use sebesar 0.377 , design/layout of page adalah 0.463 , dimana pertanyaan yang menyangkut penyajian informasi di website Livingetc, user telah puas akan penyajian informasi yang diberikan sangat berguna, lengkap, jelas, dan diperbarui dengan konten yang baru secara periodik. User setuju merekomendasikan website ini kepada orang lain.

3) Kualitas website berpengaruh pada kepuasan user dan intensitas kunjungan website dimana variabelvariabel yang diteliti berpengaruh signifikan pada kualitas website, jika kualitas website rendah, maka user tidak mendapatkan manfaat dan tidak akan kembali untuk mengunjungi website dan merekomendasikan website kepada yang lain.

Hasil penelitian ini dapat direkomendasikan pada perusahaan untuk melakukan perbaikan pada website livingetcindonesia untuk meningkatkan kepuasan user dan perlu diperhatikan perencanaan yang baik terhadap fungsi dan fitur yang tepat, design website, dan page load per halaman agar tidak memberikan kendala saat mengunjungi website livingetcindonesia.com. Penelitian ini dapat dijadikan referensi penelitian selanjutnya pada website berbeda dan kriteria lainnya yang berpengaruh pada kualitas website.

\section{DAFTAR PUSTAKA}

1. Almahamid, S. (2005). The Relationship Between Perceived Usefulness, Perceived Ease of Use, Perceived Information Quality, and Intention to Use E-Government. Journal of Theoretical and Applied Information Technology, 11(1), 3044.

2. Bailin, A., \& Pullinger, D. (2010, 10). Measuring Website Quality. Retrieved 02 12, 2012, from Central Office of Information: http://coi.gov.uk/ documents/guidance/measuring-website-qualityv1-2.pdf
3. Burton, J. (2009). Understanding the Economics of Digital Compared to Traditional Advertising and Media Services. New York: AmericaAn AssociaAtion of Advertising Agencies.

4. Clifton, B. (2010). Advanced Web Metrics with Google Analytics. Indiana Polis, Amerika Serikat: Wisley.

5. Daztbaz, M. (2003). Designing Interactive Multimedia System. New York: McGraw-Hill.

6. Hendricks, A. (2010). The Twenty First Century Media Industry. Plymouth: Lexington Books.

7. Jeffrey, R. (2003). Introduction to E-Commerce 2nd ed. New York: McGraw Hill.

8. Jim, S. (2004, February 10). 10 Steps Measuring Website Success. Retrieved 02 12, 2012, from MarketingProfs:http://www.marketingprofs.com/ 4/sterne13.asp.

9. Kent, P. (2004). Search Engine Optimization. New York: Wiley.

10. Liu, C., \& Arnett, K. P. (2000). Exploring the factors associated with Web site success. Information \& Management, 38 (1), 23-33.

11. Luis Olsina, e. a. (2006). Web Quality. Springer, 10.1007/3-540-28218-1_4, 109-142.

12. Magazines Publishers of America. (2007). How Media Drive Online Success: IncreasingWeb Traffic and Search. New York.

13. Moleong, L. J. (2004). Metodologi penelitian kualitatif. Bandung: PT. Remaja Rosdakarya.

14. Mosley, D. (1993). The Handbook of MIS Application Software Testing: Methods, Techniques \& Tools for Assuring Quality Through Testing. New Jersey: Yourdon Press Computing Series.

15. Nazir, M. (2003). Metode Penelitian. Yogyakarta: Ghalia Indonesia.

16. Olsina, L., \& Rossi, G. (1999). A Quantitative Method for Quality Evaluation of Websites and Applications. Argentina.

17. Powel. (1998). Web Site Engineering: Beyond Web Page Design. New Jersey: Prentice Hall.

18. Pressman, R. S. (2005). Software Engineering : A Practitioner's Approach (6 ed.). New York, Singapore: McGraw-Hill.

19. Shneiderman, B., \& Plaisant, C. (2010). Designing the user interface: strategies for effective human computer interaction (5 ed.). Boston: Addison Wesley.

20. Sina Sadeh, E. S. (2011). The Effects of Website Quality Dimensions on Customer Satisfaction in E-Retailing System. Middle East Journal, 10 (3), 366-369.

21. Sugiyono. (2008). Metode Penelitian Bisnis. Bandung, Indonesia: Alfabeta.

22. Suh, W. (2005). Web Engineering Principles and Techniques. New York: Idea Group Publishing. 
23. Teguh, W. (2009). 25 Model Analisis Statistik dengan SPSS 17. Jakarta: PT. Elex Media Komputindo.

24. Unica. (2011). The State of Marketing 2011: Unica's Annual Survey of Marketers. Retrieved 04 12, 2012, from www.unica.com: http://campaigns.unica.com/survey2011/Unica-s-AnnualSurvey-of-Marketers-2011_v22.pdf
25. Wikipedia. (2012, January 23). Web Usability. Retrieved 05 05, 2012, from Wikipedia: http://en. wikipedia.org/wiki/Web_usability.

26. Yin, R. K. (2003). Study Research: Design and Methods (Thrid Edition) (Vol. 5). Washington DC: Sage Publication. 